\title{
Formulating Environmentally Friendly Oil- Base Mud using Soybean Oil
}

\author{
Taher El Fakharany ${ }^{1,2}$, Ahmed Abdel Geliel ${ }^{2}$, Hadir Salhin ${ }^{2}$ \\ Mining and Petroleum Engineering Department, Faculty of Engineering, Al-Azhar University, Cairo, Egypt ${ }^{1}$ \\ Petroleum and Energy Engineering Department, the American University in Cairo (AUC) ${ }^{2}$
}

\begin{abstract}
Today, the use of diesel in oil base mud is either prohibited or severely condemned due to its environmental impact. It also faces the obstacle of high disposal costs enforced by regulations set to lessen the environmental damage caused. This is forcing the industry to shift away from its use as it is becoming less feasible to operate with. A substitute base mud should be formulated in order to decrease the environmental impact, simultaneously abiding by regulations and in turn lower the overall costs. The focus on formulating a substitute-based mud using vegetable oils rather than diesel oil is gaining strong ground in the oil industry. Of these vegetable oils, Soybean oil shows great potential in both its characteristics and formulation cost. This paper is a stepping-stone into researching the feasibility of this oil. It discusses the approach that will be taken to assess Soybean oil base as oil base mud in order to conclude whether it is viable to be used as an OBM. The experimental work carried out showed high potential of Soybean base mud in comparison to oil base in both physiochemical and rheological properties as an oil and drilling fluid, better thermal stability in HPHT wells, safe due to its fire capacity resistance. The prepared Soybean base mud will perform the same function as diesel base mud, but more efficiently with less frictional pressure losses. Finally Soybean oil base mud is less expensive than oil base mud with less environmental impact and can be applied in the industry.
\end{abstract}

Keywords: soybean oil, oil-Base Mud, Diesel, drilling fluid, biodegradable oils, toxicity.

\section{INTRODUCTION}

Drilling fluids make up a crucial part of the drilling operation. The term drilling fluids or drilling mud usually refers to fluids that assist in well control and the removal of cuttings from the bottom of the hole up to the surface [1]. These fluids, depending on their base are a mixture of oil, water, clays and certain chemicals. Superior circulation fluids can complete the drilling process rapidly, safely and economically. The drilling fluid is not a multi-tasked system; it is a fluid with accurate rheology prepared to perform a certain task. To execute this task perfectly, precise drilling fluid design is stalwartly desired. This design must account for; the well design, anticipated formation pressures and rock properties, formation chemical properties, temperature, environmental regulations logistics and cost [2]. With the development of new drilling techniques such as long deviated well; high-pressure high temperature wells and deep marine wells, the quality and performance of the used mud require to be enhanced.

The rheology of the mud determines its effectiveness in drilling a well [3]. The effectiveness or the performance of the drilling fluid is measured by the capability of the fluid to accomplish its job. The prime use of the drilling fluid is to remove the formation cuttings within the well. The designed fluid should carry and suspend the cuttings while in circulation and transmitted securely through the annulus incurring minimum losses and environmental impact [4]. The selection and formulation of the fluid is done by the mud engineer, who determines the required viscosity, density, fluid loss control, chemical composition and many other properties of the mud [5].The selection of the type of the drilling fluid is based on three important factors; the cost, technical performance and the environmental impact of the fluid on the formation. The selection of the best suiting type is important as it defines the success of the drilling operation. In recent years, researchers have focused on formulating a biodegradable oil base-mud that would save on cost of disposal, and simultaneously have less of a negative impact on the environment [6]. The vegetable oils are a proposed solution to replace the current oils use in the oil base muds. The soybean oil was made based on availability, cost, ease of extraction and certain characteristics the oil possess that makes it a potentially better aspirant than oil base mud.

\section{LITERATRURE REVIEW \& PROBLEM OF STATEMENT}

In recent years many legislations and restrictions enforced have made diesel unfavorable to work with throughout the drilling process [7]. An integrated solution to this problem is needed using systematic and quantitative studies to come up with an applicable drilling fluid. This solution must cover aspects of performance and cost in order to be truly sufficient to use. Now a direction of focus went to formulating a biodegradable oil base mud. This type of mud would cause a much lower environmental impact leading to a reduction in cast and simultaneously have the same properties as 
current oil base muds [8]. The final results of these studies can be considered as a proposals to replace the current oil used in drilling operations with vegetable oils.

After discussing the negative environmental impacts and the enforced regulations and legislations that banned the diesel base mud. It is sensible to discuss the pros the vegetable oils and how it gained potential to replace the diesel in formulating the oil base mud. the vegetable oils are like Soy bean oil, Palm oil ,Groundnut oil ,Jatropha oil ,Canola oil ,Algae oil ,Castor oil ,Sun flower oil,..... Etc. The vegetable oils contain a number of triglycerides of fatty acids which are esters of fatty acids with glycerol [9]. The nature of the fatty acids and their relative amounts in given oil has significant influence on the physio-chemical and mud making properties of the oil. One of the vital characteristics of vegetable oils, that it has better oxidation stability and of course highly biodegradable. Some of the advantageous vegetable oil properties will be compared to the diesel and also some of the limitation will be elaborated. Soy bean oil is the world's most widely used edible oil and commonly called "Vegetable oil". The soy bean oil is common and popular, because it is cheap, healthy, has high smoke point and can be utilized in several industries. The soy bean oil is free from Trans fats and contains low amount of saturated fats. Soy bean has the potential to pass all aspects of our selection criteria affecting both economy and environment. The cost of soy bean oil, internationally a barrel of soy bean oil costs $\$ 1.08$ / liter which is almost similar to the cost of diesel making it an insignificant factor in our comparison [10]. The details of the cost are shown in the Table (1) that shows that the use of soy bean oil becomes feasible in the future where the price of one liter drops against the price of diesel oil.

The work in this paper can be summarized into four clear steps:

- Collection of materials (diesel oil, Soybean oil)

- Comparison between the physicochemical properties of diesel oil and Soybean oil

- Formulation of the new drilling fluid

- Rheological comparison between the two mud samples

\section{MATERIAL SELECTION AND EXPERMENTAL WORK}

In our experimental program, it will start by formulating the common diesel base mud samples, as their properties are available and then start to formulate the soy bean oil base mud to start the rheological comparison. The soybean oil is extracted from soybean seeds using the soxhlet extraction method. Before grinding the seeds the outer layer must be removed. The solvent extraction was the chosen method as many researchers and industries used this certain method of extraction. Soxhlet extraction method can extract about $99.5 \%$ of the oil in the seed. This method proves to be highly efficient as it leaves approximately $0.5 \%$ residual oil. A low boiling solvent is used for extraction; the $\mathrm{n}$ - hexane is the most common chosen solvent for heating.

The grounded seeds and the n-hexane are put together in the boiling flask and heated to $140 \mathrm{~F}$. The target temperature is not high giving our work a good chance for accurate experimentation. During the process, the solvent vapor will move up to the distillation column, enter the condenser and then this condensed vapor is returned back into the flask to enrich the samples. This method is repeated until the required amount is extracted. The last step in this extraction method is to separate the mixture of the n-hexane and the soybean oil. It can be separated easily with any mean. The separation can be done using a steam bath. In the steam bath, the solvent is evaporated and the required soybean oil is kept alone. Also, the mixture can be separated by just heating the mixture, so the solvent will evaporate early as it has low boiling point and the soy bean oil will be kept alone. To check that the soy bean oil is now free from the n-hexane, just calculate the density of the sample and check it with the theoretical density, knowing the density of soy bean oil being $0.917 \mathrm{gm} / \mathrm{mL}$.

\section{Physiochemical properties:}

The next step was testing the physicochemical properties, which provided an early sign of desirability of the formulated mud base on favorable criteria. The four properties selected to compare were density, plastic viscosity, pour point and flash point, all are measured in the PVT lab.

\section{Results of the Physiochemical properties:}

1) Density: the results showed that Soy bean oil mud densities were significantly higher than diesel oil mud. However a benefit of the higher densities of Soy bean are that less barite could be used, that reduce the total cost of formulation.

2) Plastic viscosity of Soy bean oils showed a much higher viscosity than diesel oil mud. So, the use of viscosity modifiers and reducers must be used. That being said, treating an oil for high viscosity is more favorable than treating a low viscosity oil. This is due to the favorable properties highly viscous oils contain, acting as a water base mud without being water wet and therefore unable to perform in necessary extreme conditions. This results in the need to repeat formulation steps to acquire the correct oil/water and viscosity modifier ratios. 
3) Pour point: the results showed that soy bean oil mud Pour point were significantly higher than diesel oil mud, this advises that it should not be used in cold environments. Since the Soybean is more suitable in Egypt, with a hot and relatively stable climate.

4) Flash point: soy bean oil mud showed a high flash and fire temperatures, which have proven difficult to achieve in a university lab. Results of the four parameters are shown in Table (2).

\section{Mud Formulation and Rheological Properties:}

First of all we formulating a sample of drilling mud from each type and testing its rheological properties as criteria to select the most suitable and advanced drilling mud in order to replace the currently used diesel.

\section{Mud Density}

The first vital indicator of the mud quality was the mud density. After preparing a mud sample with different amounts of barite. It is crucial to determine the influence of the barite on the mud sample in order to reach the ideal density that is used in the oil industry. The results of the effect of barite on Soy bean obtained are shown in Table (3). The density of the 10 gram barite was the most reliable comparing to most drilling operations having a density of mud of approximately $8 \mathrm{lb} / \mathrm{gal}$.

\section{FAN V-G Viscometer Rheological Properties}

The rheological results of the diesel base mud and Soy bean oil mud are illustrated in Table (4).

\section{Mud Filtration Test}

The mud filtration test is done using the standard API filter press by applying differential pressure. The pressure applied in our university laboratory was $100 \mathrm{psi}$ and the mud cup was attached to the pressure valve and left for 30 minutes, while collecting the filtrate within the 30 minutes. The filtrate results of the Soybean oil base mud yielded are more favorable than oil base mud, shown in Table (5). The Soybean oil base mud had the lowest mud cake thickness.

\section{PH Results}

The drilling fluid has to have a certain PH value which cannot be exceeded or gone below. During formulation we added a PH enhancer; NAOH formulating two samples: one with $\mathrm{NAOH}$ and one without to see whether it would be beneficial. Therefore, the PH measurement was only measured for the best sample, PH value of Soy bean oil base mud $=9$.

\section{Diesel Base Mud}

The first indication of the prepared samples should be figured out using the common sense and the experience with a lot of samples. After shutting off the mixer and now the mud should be ready to use, the drilling fluid should be partially homogenous and no one of the components can be seen alone. Also, the color of the mud and viscosity could be the first indicators, where we take a decision to complete with this sample or should repeat and prepare new sample, shown in Table(6).

\section{Soy bean Base Mud}

The preparation of the soybean oil mud can be considered as the most challenging. To come up with formulated mud with the soybean oil took around 7 samples until an acceptable mud sample was reached. The soybean oil was extracted from the soybean seeds using the soxhlet extractor in the core university lab. The soxhlet extractor is only capable of extracting small quantities and takes a long period of time, leading to the use of commercial soybean oil. Certain factors are adjusted to obtain the most suitable results by:

- Adding a viscosity reducer which was EMEC - WET

- Decreasing amount of barite (weighting agent)

- Decreasing the amount of bentonite (viscosifier)

- Increase the mixing time during some phases

These were the methods utilized to reach the ideal sample of the soybean oil base mud. The first effective method was to add a viscosity reducer to decrease the viscosity of the mud sample. When we decrease the amount of barite, it will decrease the density and weight of the mud making it more suitable. However, decreasing the amount of the bentonite was unbeneficial and the mud remained viscous, shown in Table (7). The last method was waiting a longer period of time after adding the water during the formulation.

\section{DISCUSSION OF THE RESULTS}

When comparing Soy bean oil base mud with diesel oil base mud, Soy bean density is higher than diesel. This provides the advantage of higher density, leading to applicability of carrying drilled cuttings. Another advantage of Soy 
bean oil base mud is its greater ability to increase its weight. As the results showed, Soy bean oil base mud increased from $10.5 \mathrm{lb} /$ gallon to $12 \mathrm{lb} /$ gallon by adding only 5 gram of barite which is a $12.5 \%$ increase. Meanwhile, diesel only increased by $6 \%$ by applying the same amount of barite to the sample.

Soy bean oil base mud, yielded appealing results, proving its potential to replace diesel base mud. Soy bean oil base mud has a more ideal yield point value than diesel base mud. A drawback of diesel base mud is its high yield point which leads to high pressure losses. The prepared Soy bean base mud will perform the same function as diesel, but more efficiently with less frictional pressure losses. In addition to this, Soy bean base mud has a plastic viscosity of 14 $\mathrm{cp}$, while diesel base mud is $16 \mathrm{cp}$. It is not a drastic difference, but the lower the plastic viscosity the less resistance to flow. If Soy bean oil base mud is used in drilling operations it may require less circulation pressure. Lower circulation pressure will lead to lower pumping costs and reduce the chances of losing circulation during drilling.

The gel strength is a very good parameter in evaluating the mud performance. There isn't a large difference between the gel strength of Soy bean and the diesel oil, they both have a good gel structure. These rheological results showed that Soy bean has strong potential to replace diesel.

The filtration results showed that Soy bean oil base mud collected less water and oil volume as filtrate. Diesel oil base mud follows with higher filtrate volumes. Higher oil and water filtrate volumes indicate that the drilling fluid failed to achieve stable emulsion between the oil and water. Therefore, Soy bean oil base mud is considered to be a better alternative than the diesel base mud by achieving stronger emulsion between the oil and water. In Table (5), soy bean base mud showed higher performance than diesel base mud, as the measured mud cake thickness was only 2.5 $\mathrm{mm}$. However, the diesel base mud sample generated $3 \mathrm{~mm}$ mud cake thickness and was more porous.

\section{CONCULSIONS}

The oil and gas industry is being weighed down by laws and regulations regarding toxic oil base-drilling fluid and its impact on the environment. This accompanied by disposal costs is forcing the industry to search for applicable substitutes to the currently used oil base mud and Soy bean oil are presented as potential candidates to make this transition. The Paper showed that high potential of soy bean oil base mud in comparison to oil base mud in both physiochemical and rheological properties as an oil and drilling fluid. Toxicity of Soy bean oil base is less than oil base mud. Soy bean oil base has better thermal stability in HPHT wells, more safe due to its fire capacity resistance, less filter loss \& mud cake thickness, better density than oil base mud and gel strength.

Finally the comparison showed soy bean oil is less harm to the environment, less expensive and more efficient than diesel base mud so Soy bean can be applicable as a substitute to oil base mud.

\section{REFERENCES}

[1] Amanullah, M. 2005. Physio-Chemical Characterisation of Vegetable OIls and Preliminary Test Results of Vegetable-Oil-Based Muds. Presented at the SPE/IADC Middle East Drilling Technology Conference and Exhibition, Dubai, United Arab Emirates. SPE-97008.

[2] Dosunmu, A. 2010.Development of Environmentally Friendly Oil Based Mud using Palm-Oil and Groundnut-Oil. Presented at the 34th Annual SPE International Conference and Exhibition, Calabar, Nigeria, 31 July - 7 August. SPE-140720.

[3] Taher El Fakharany, Roshdy Khaled, Amr Mahmoud.2017. Formulating Environmentally Friendly Oil- Base Mud using Jatropha Oil. IARJSET, Vol. 4, Issue 1, January 2017

[4] Walker, Jonathan, Miller, J. J., Burrows, Kim, Hovan, Jared, Mander, Timothy.2016. Improving the Environmental Impact of Drilling Fluids: Case History of a New, Salt-Free, Non-Aqueous Fluid. SPE -179265-MS Conference.

[5] Bland, R. G., Mullen, G. A., Gonzalez, Y. N., Harvey, F. E., \& Pless, M. L. (2006, January 1). HPHT Drilling Fluid Challenges. Society of Petroleum Engineers. doi:10.2118/103731-MS.

[6] Hussein, A.M.O. and Amin, R.A.M. 2010. Density Measurement of Vegetable and Mineral Based Oil Used in Drilling Fluids. Presented at the 34th Annual SPE International Conference and Exhibition, Calabar, Nigeria, 31 July -7 August

[7] Li, Wai, Zhao, Xionghu, Ji, Yihui, Peng, Hui. 2016. Investigation of Biodiesel-Based Drilling Fluid, Part 1: Biodiesel Evaluation, InvertEmulsion Properties, and Development of a Novel Emulsifier Package. 180918-PA SPE.

[8] Gbadebo, A.M., Taiwo, A.M and Eghele, U.. (2010). Environmental Aspect of Oil and Water-Based Drilling Muds and cuttings from Dibi and Ewan offshore wells, Niger delta, Nigeria.African Journal of Environmental Science and Technology. 4(5):284-292.

[9] Lang, Andrew, and Hazir Farouk Abdelraheem Elhaj. "Jatropha Oil Production for Biodiesel and Other Products." (2013): n. pag. Web. 25 Dec. 2015.

[10] Agwu, O.E., Isemin, I.A., and Akpabio, M.G. 2015. Cost Benefit Analysis of Vegetable Oils Used As Alternatives to Diesel in the Formulation of Oil-Based Drilling Muds. Presented at the Nigeria Annual International Conference and Exhibition, Lagos, Nigeria, 4-6 August.SPE-178265.

Table 1: Comparison between the average price (US Dollars) per barrel of soy bean and oil base mud

\begin{tabular}{|c|c|c|}
\hline Year & Soybean $\mathbf{( \$ / b b l . )}$ & Diesel oil (\$/bbl.) \\
\hline 2009 & 119.58 & 81.48 \\
\hline 2010 & 135.39 & 92.22 \\
\hline 2011 & 177.98 & 126.63 \\
\hline 2012 & 168.61 & 130.76 \\
\hline 2013 & 147.98 & 126.66 \\
\hline 2014 & 123.68 & 124.46 \\
\hline
\end{tabular}


UGC Approved Journal

Table 2: physicochemical properties results

\begin{tabular}{|c|c|c|c|c|c|c|}
\hline Property & $\begin{array}{l}\text { Density } \\
(\mathrm{kg} / \mathrm{m} 3)\end{array}$ & $\begin{array}{ll}\text { Pour Point } \\
{ }^{\circ} \mathbf{C}\end{array}$ & $\begin{array}{l}\text { Flash } \\
\text { Point }{ }^{\circ} \mathrm{C}\end{array}$ & $\begin{array}{l}\text { Fire } \\
\text { Point }{ }^{\circ} \mathrm{C}\end{array}$ & $\begin{array}{l}\text { Kinematic } \\
\text { Viscosity @ } 40^{\circ} \mathrm{C}\end{array}$ & $\begin{array}{l}\text { Aromatic } \\
\text { Content }(\%)\end{array}$ \\
\hline $\begin{array}{l}\text { Base oil Required } \\
\text { Properties }\end{array}$ & N/A & $\begin{array}{l}<\text { Ambient } \\
\text { Temperature }\end{array}$ & $>66$ & $>80$ & 2.3-3.5 & $4-8$ \\
\hline Diesel Oil & 830 & -18 & 66 & 108 & $2.7-3.4$ & $25 \% \mathrm{v} / \mathrm{v}$ \\
\hline Soybean Oil & 920 & -20 & 330 & 342 & 31.8 & N/A \\
\hline
\end{tabular}

Table 3: Density of Diesel base mud and Soy bean base mud with different barite content

\begin{tabular}{|l|l|l|}
\hline Barite Content (grams) & Diesel Base Mud, lb/gal & Soy bean Base Mud, lb/gal \\
5 & 7.3 & $\mathbf{1 0 . 5}$ \\
\hline 10 & $\mathbf{8 . 1 0}$ & $\mathbf{1 2}$ \\
\hline
\end{tabular}

Table 4: Rheological results of diesel base mud and Soy bean base mud

\begin{tabular}{|l|l|l|}
\hline Rheological Parameters & Soy bean base mud & Diesel base mud \\
Plastic viscosity & $14 \mathrm{cp}$ & $15 \mathrm{cp}$ \\
\hline Yield point & $14 \mathrm{lb} / 100 \mathrm{ft}^{2}$ & $16 \mathrm{lb} / 100 \mathrm{ft}^{2}$ \\
\hline Apparent viscosity & $21 \mathrm{cp}$ & $23 \mathrm{cp}$ \\
\hline Gel strength $(10$ seconds) & $5 \mathrm{lb} / 100 \mathrm{ft}^{2}$ & $7 \mathrm{lb} / 100 \mathrm{ft}^{2}$ \\
\hline Gel strength (10 minutes) & $6 \mathrm{lb} / 100 \mathrm{ft}^{2}$ & $9 \mathrm{lb} / 100 \mathrm{ft}^{2}$ \\
\hline
\end{tabular}

Table 5: Filtration results of diesel base mud and Soy bean base mud

\begin{tabular}{|l|l|l|}
\hline Filtrate Properties & Soy bean base mud & Diesel base mud \\
Total fluid volume & $35 \mathrm{ml}$ & $30 \mathrm{ml}$ \\
\hline Oil volume & $15 \mathrm{ml}$ & $11 \mathrm{ml}$ \\
\hline Water volume & $20 \mathrm{ml}$ & $19 \mathrm{ml}$ \\
\hline Mud cake thickness & $2.5 \mathrm{~mm}$ & $3 \mathrm{~mm}$ \\
\hline
\end{tabular}

Table 6: Diesel base mud components

\begin{tabular}{|c|c|c|c|c|}
\hline Mud Component & Component Name & Component Quantity & $\begin{array}{l}\text { Mixing Duration } \\
\text { (mins) }\end{array}$ & $\begin{array}{l}\text { Mixing } \\
\text { Order }\end{array}$ \\
\hline Non-wetting Agent & Diesel Oil & $245 \mathrm{ML}$ & - & 1 \\
\hline Primary Emulsifier & EMEC PEMUL1000 & $6 \mathrm{ML}$ & 2 & 2 \\
\hline Secondary Emulsifier & EMEC-SEMUL100 & $4 \mathrm{ML}$ & 5 & 3 \\
\hline Filter Loss Agent & Hydroxyl ethyl cellulose & $0.35 \mathrm{~g}$ & 5 & 4 \\
\hline Wetting Phase & Water & $105 \mathrm{ML}$ & 16 & 5 \\
\hline Viscosifier & Bentonite & $25 \mathrm{~g}$ & 4 & 6 \\
\hline PH Enhancer & $\overline{\mathrm{NAOH}}$ & $0.25 \mathrm{~g}$ & 5 & 7 \\
\hline Weighting Agent & Barite & 10 gram & 8 & 8 \\
\hline
\end{tabular}

Table 7: The composition of Soy bean base mud

\begin{tabular}{|l|l|c|c|c|}
\hline Mud Component & Component Name & Component Quantity & Mixing Duration (mins) & Mixing Order \\
\hline Non-wetting Agent & Soy bean Oil & $220 \mathrm{ML}$ & - & 1 \\
\hline Primary Emulsifier & EMEC PEMUL1000 & $6 \mathrm{ML}$ & 2 & 2 \\
\hline Secondary Emulsifier & EMEC-SEMUL100 & $4 \mathrm{ML}$ & 5 & 3 \\
\hline Filter Loss Agent & Soda Ash & $0.35 \mathrm{~g}$ & 5 & 4 \\
\hline Wetting Phase & Water & $105 \mathrm{ML}$ & 20 & 5 \\
\hline Viscosifier & Bentonite & $20 \mathrm{~g}$ & 8 & 6 \\
\hline PH Enhancer & NAOH & $0.25 \mathrm{~g}$ & 3 & 7 \\
\hline Weighting Agent & Barite & $6 \mathrm{gram}$ & 10 & 8 \\
\hline Viscosity Reducer & EMEC WET & $10 \mathrm{ML}$ & 10 & 9 \\
\hline
\end{tabular}

